\title{
Postoperative Spindle Cell Nodule of the
} Cervix

National Cancer Institute

\section{Source}

National Cancer Institute. Postoperative Spindle Cell Nodule of the Cervix. NCI

Thesaurus. Code C128051.

A rare, benign, non-neoplastic reactive lesion that develops in the cervix at the site of a prior operative procedure. It is composed of spindle cells, small blood vessels, and chronic inflammation. 